\title{
TAM MODEL FOR E-HEALTH IMPLEMENTATION IN RURAL AREAS OF UTTARAKHAND, POST COVID-19 PANDEMIC
}

\section{---TAM Model for E-Health Implementation: A Study of Rural Areas of Uttarakhand During Post Covid}

\author{
Pushpa Katarial, G.P. Dang2, Divneet Kaur33, Prashant Singh4, Vijay Prakash Gupta5 \\ 1.4. Doon Business School, Dehradun, India \\ 2.3. Department of Commerce, D.A.V.(P.G.) College, Dehradun, India \\ 5. ITS Gaziabad, India
}

Correspondence: pushpakataria22@gmail.com

\section{ABSTRACT}

\section{OBJECTIVE:}

The present study aim to find out the factors that has an influence and impacts the actual use of e-Health during post COVID-19 pandemic on the lines of TAM (technology acceptance model) and further suggest ways for effective implementation and adoption of e-Health by the rural patients.

\section{DESIGN \& SETTING:}

The study was conducted on a total of 243 rural patients who had experienced e-Health services. Structural Equation Modeling has been used for analysis of data.

\section{RESULTS:}

The analysis revealed that 'perceived usefulness', 'perceived ease of use', 'privacy' and 'trust', all had considerable impact on the 'intention to use' which further significantly impacts the 'actual use'.

\section{CONCLUSION:}

Using in-depth interviews, both patients and physicians, practice of evidence-based e-Health interventions was identified for effective implementation and adoption of e-Health, which further helps to provides an equitable healthcare services to both urban and rural population.

\section{KEYWORDS}

e-Health, Uttarakhand, rural population, evidence-based e-Health. 
The holistic development of an economy majorly depends on a healthy and skilled and productive workforce [1]. The advent of technology in health has substantially transformed the health system in the country. E-Health has played a significant role in reaching to human aid including those who cannot afford basic healthcare services [30]. A lot of research work has been conducted in health sector for delivering a seamless experience with e-Health facilities. [25] For effective utilization of e-Health, it is important to study factors that affect the acceptance and adoption of e-Health services by both the patients and the medical practitioners. [5] [17] [25] Researches in this field have explored numerous models to deliver effective e-Health services in the rural and interior areas as a social measure. [5] [22] Uttarakhand being a hilly state, provision of e-Health services to the entire state sometime poses a major challenge. Hence the 'Technology Acceptance Model' has been explored to determine factors influencing the adoption of the e-Health model for rural and interior areas of Uttarakhand in creation of trust and comfort level among the patients.

\section{THEORETICAL BACKGROUND AND HYPOTHESES FORMULATION}

The study aims to find out the vital factors that influence the adoption of e-Health in the rural areas of Uttarakhand by utilizing the TAM during the post Covid-19 pandemic. The Technology Acceptance Model (TAM) is a popular model to understand and recognize "why users/customers accepts or rejects a technology and also how user/customer acceptance can be enhanced through technology." The TAM was originally developed by Fred D. Davis in 1980s. [12] Further the basic TAM has been added other extensions to reduce the limitations with the traditional model. [1 1] [14]

The basic TAM model includes 'Perceived Usefulness' and 'Perceived Ease of use' that the users have experienced with the technology which contributes to their 'intention to

use' e-Health services. [25] Perceived usefulness is defined as the "degree by which a person considers that by using a specific technology leads to enhancement ones performance" while perceived ease of use is believed as the extent to which a person understands that by using a particular system will result in free of efforts or less effort". Thus, TAM has provided a framework to understand that the patient's 'intention to use' get converted into actual use of e-Health.[29] In addition to factors 'Perceived Usefulness' and 'Perceived Ease, other factors in TAM that the study has investigated to study were 'privacy' and 'trust'. [2] Researchers highlighted few other factors in addition to the ones included in basic TAM model - acceptance of users, attitude of the doctors, adoption by doctors, social and cultural factors, technological infrastructure, supporting healthcare structure, etc. [15][16] The patients, especially those residing in rural areas hesitated to use e-Health services with the viewpoint that using technology can expose their private information in jeopardy leading to lack of trust in e-Health. [26-28] Patients were comfortable to share their medical history and information with only the doctors or medical associates. [15-16] Further the relationship between trust and the acceptance of technology by the user was realized. [7] The trust on technology is based on the experience and the probable threat that it entails. Therefore, it has been found that during post Covid-19 situation, acceptance of technology significantly impacted the trust and vice versa. Sharing medical information through digitalized process created discomforts among patients due fear of information leak.

\section{Hypothesis}

$\mathrm{H}_{01}=$ There is no significant impact of perceived usefulness on intention to use

$\mathrm{H}_{02}=$ There is no significant impact of perceived ease of use on intention to use

$\mathrm{H}_{03}=$ There is no significant impact of privacy on intention to use

$\mathrm{H}_{04}=$ There is no significant impact of trust on intention to use $\mathrm{H}_{05}=$ There is no significant impact of intention to use on the actual use 


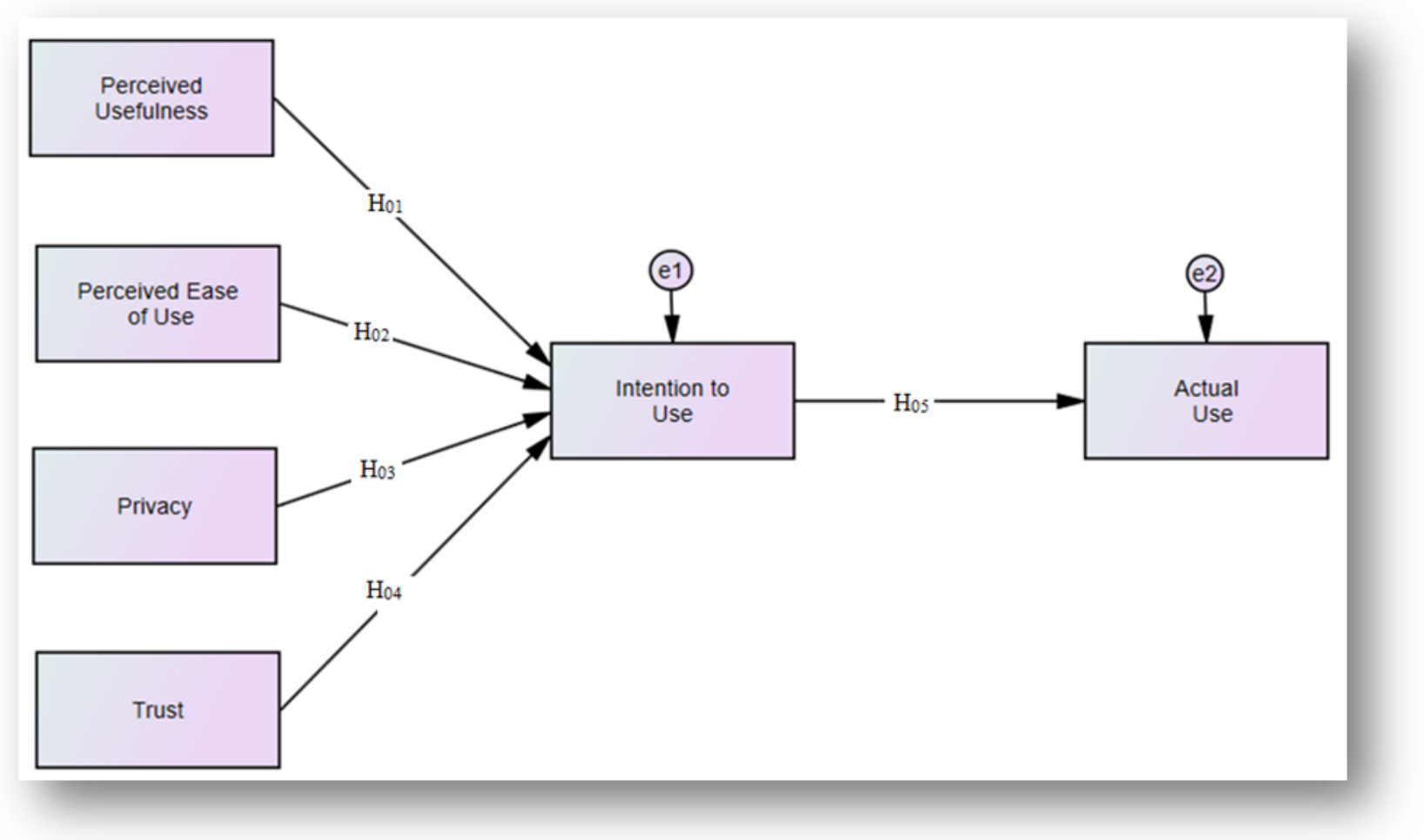

\section{RESEARCH METHODOLOGY}

\section{RESEARCH SETTING}

The present research intended to study significant factors that affects the 'intention to use' and 'actual use' of the eHealth services during post pandemic situation and to design a suitable model for optimum utilization of e-health services among rural patients in Uttarakhand; for which positivist approach proved appropriate.[17] The TAM model in the present study included privacy and trust in addition to perceived usefulness and perceived ease of use.

\section{MEASURES}

The variables used in the model were adapted as per the need of the study. The traditional I TAM model included perceived usefulness, perceived ease of use, intention to use and actual use which were extracted from Davis [10], Venkatesh and Davis, [27] Taylor and Todd. [24] The additions of trust and privacy were adapted from Featherman and Pavlou [9], Giovanis et al. [11] Chellappa and Pavlou [4] and Korgonkar andWolin [19] respectively.

\section{DATA COLLECTION}

Primary data has been collected using a structured questionnaire from respondents which primarily consisted patients/ patients' attendant group. The data has been collected from district hospital at Tehri Garhwal and from community health centers ( $\mathrm{CHCs}$ ) each at Beleshwar and Devprayag, Srinagar in Garhwal and Almora \& Rudrapur districts of Kumaun regions. A total 350 respondents were contacted out of which 243 responses were chosen for analysis due to completeness and error free feedback. Further factors of e-health were first reviewed and verified through both internal checks and delphi technique. The secondary data has been collected from statistics and literature available with the government and nongovernment bodies.

\section{STATISTICAL TOOLS \& DATA ANALYSIS}

The data collected was analyzed using AMOSS- SEM using TAM (Technology Acceptance Model) model. Multiple Regression Analysis tool has been explored in the study. Data analysis is covered in two sections: Measurement model and structural model.

\section{MEASUREMENT MODEL}

The measurement model has been run to check the construct validity which included both discriminant as well as convergent validity along with checking the model fit as well. The factors along with their variables were run to 
check for model fit and construct validity which provided the following results. The model fit indices included CMIN/df=1.526; GFI=0.913; NFI=0.966; $\mathrm{CFI}=0.988 ; \mathrm{TLI}=0.985$ and RMSEA $=0.047$ which were all according to the recommended guidelines. [3],[11]

\section{TABLE 1: MODEL FIT INDICES}

\begin{tabular}{|l|l|l|}
\hline MODEL FIT INDICES & VALUES & RECOMMENDED GUIDELINES \\
\hline GFI & 0.913 & $\geq 0.90$ \\
\hline$X^{2} / D F$ & 1.526 & $<5$ \\
\hline RMSEA & 0.047 & $<0.08$ \\
\hline NFI & 0.966 & $\geq 0.90$ \\
\hline CFI & 0.988 & $\geq 0.90$ \\
\hline TLI & 0.985 & $\geq 0.90$ \\
\hline
\end{tabular}

\section{TABLE 2: MEASUREMENT MODEL}

\begin{tabular}{|c|c|c|c|c|c|}
\hline CONSTRUCTS & ITEMS & LOADINGS & CR & $\begin{array}{l}\text { CRONBACH } \\
\text { ALPHA }\end{array}$ & $A \bigvee E$ \\
\hline Perceived Usefulness (PU) & $\begin{array}{l}\text { PU1 } \\
\text { PU2 } \\
\text { PU3 } \\
\text { PU4 }\end{array}$ & $\begin{array}{l}.940 \\
.948 \\
.888 \\
.946\end{array}$ & 0.963 & 0.87 & 0.866 \\
\hline Perceived Ease of Use (PEU) & $\begin{array}{l}\text { PEU1 } \\
\text { PEU2 } \\
\text { PEU3 } \\
\text { PEU4 }\end{array}$ & $\begin{array}{l}.956 \\
.953 \\
.969 \\
.956\end{array}$ & 0.984 & 0.89 & 0.940 \\
\hline $\begin{array}{l}\text { Privacy } \\
\text { (PRI) }\end{array}$ & $\begin{array}{l}\text { PRI1 } \\
\text { PRI2 } \\
\text { PRI3 }\end{array}$ & $\begin{array}{l}.951 \\
.972 \\
.968\end{array}$ & 0.927 & 0.91 & 0.810 \\
\hline $\begin{array}{l}\text { Trust } \\
\text { (TRU) }\end{array}$ & $\begin{array}{l}\text { TRU1 } \\
\text { TRU2 } \\
\text { TRU3 }\end{array}$ & $\begin{array}{l}.959 \\
.959 \\
.966\end{array}$ & 0.970 & 0.91 & 0.916 \\
\hline $\begin{array}{l}\text { Intention to Use } \\
\text { (INT) }\end{array}$ & $\begin{array}{l}\text { INT1 } \\
\text { INT2 } \\
\text { INT3 }\end{array}$ & $\begin{array}{l}.921 \\
.840 \\
.939\end{array}$ & 0.974 & 0.81 & 0.925 \\
\hline $\begin{array}{l}\text { Actual Use } \\
\text { (ACT) }\end{array}$ & $\begin{array}{l}\text { АCT1 } \\
\text { АCT2 } \\
\text { АСТ3 }\end{array}$ & $\begin{array}{l}.963 \\
.970 \\
.926\end{array}$ & 0.966 & 0.84 & 0.904 \\
\hline
\end{tabular}


Table 2 below shows items under each factor along with their corresponding factor loadings. The variables under each factor had a factor loading above 0.70 indicating a strong convergence with their respective factors. To examine the internal reliability, Cronbach alpha and composite reliability were calculated, Values obtained were above 0.70 mark, proving it to be acceptable indicator of internal reliability.
The construct validity was calculated with the help of Dr.Gaskin's stats tool package, which provided us with the table 2 and Table 3. The criteria for convergent validity was met as the AVE values so obtained were more than 0.05 (Perceived Usefulness=0.866; Perceived Ease of Use $=0.940$; Privacy $=0.810$; Trust $=0.916$; Intention to Use $=0.925$ and Actual Use $=0.904)$.

TABLE 3: CORRELATION MATRIX AND SQUARE ROOT OF AVE

\begin{tabular}{|l|l|l|l|l|l|l|}
\hline & PEU & INT & PU & TRU & PRI & ACT \\
\hline PEU & 0.970 & & & & & \\
\hline INT & 0.014 & 0.962 & & & & \\
\hline PU & 0.325 & 0.041 & 0.931 & & & \\
\hline TRU & -0.055 & -0.165 & -0.038 & 0.957 & & \\
\hline PRI & 0.266 & 0.122 & 0.321 & -0.045 & 0.900 & \\
\hline ACT & -0.013 & -0.229 & -0.051 & -0.155 & 0.077 & 0.951 \\
\hline
\end{tabular}

FIGURE 2: STRUCTURAL MODEL

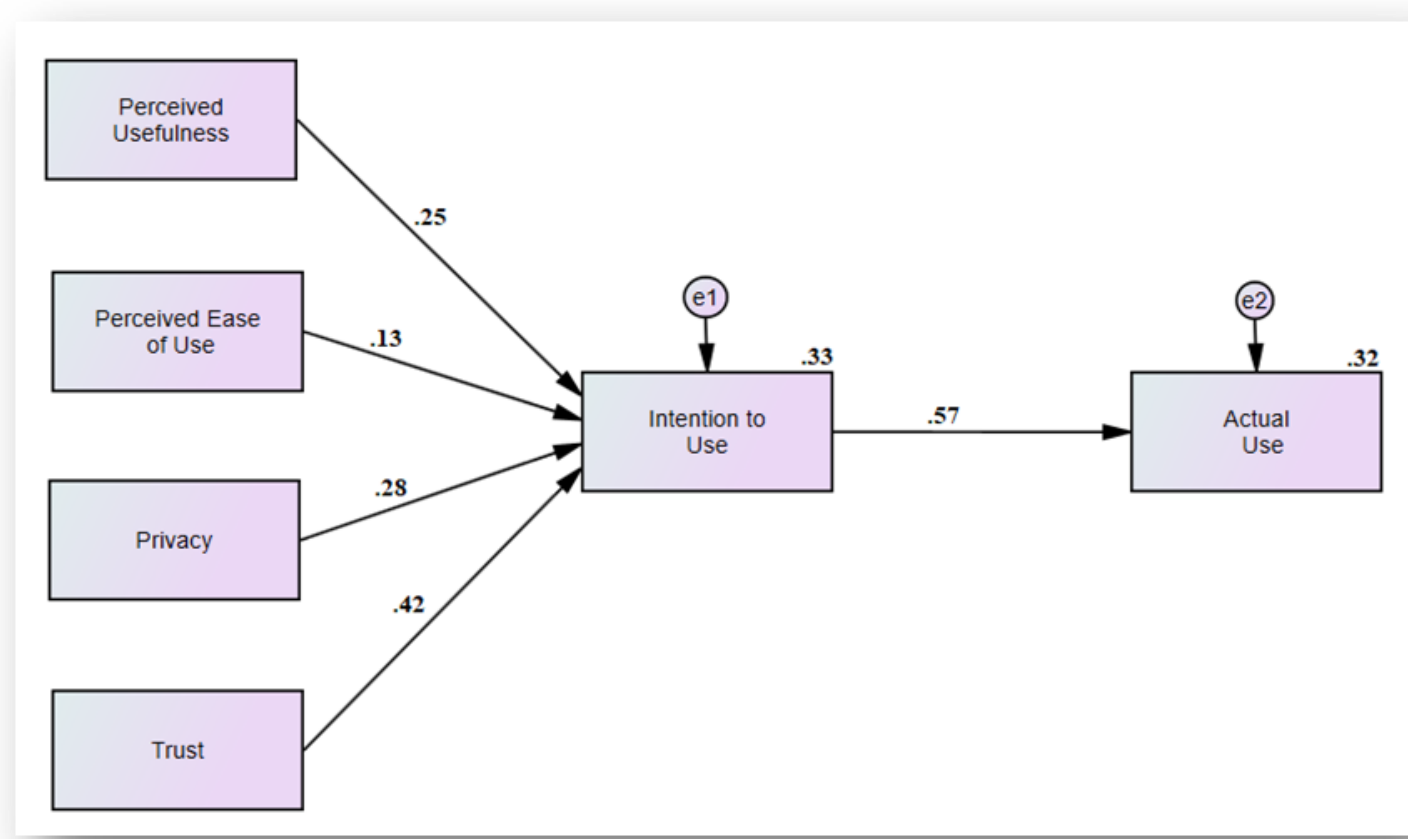


The above table depicts the correlation matrix and square root of AVE. The discriminant validity of the variables in each factor is established as the values of square root of AVE for each factor is more than the correlation value that exists between them.

\section{STRUCTURAL MODEL}

To test the hypotheses so framed, the theoretical model was explored as to examine the impact of each independent factor on 'intention to use' and further analyses the impact of intention to use on actual use (Given in Fig 2- Structural Model).

Hypothesis one intended to examine whether 'perceived usefulness' has any significant impact on 'intention to use' in the present study. The result obtained a C.R. value of 4.651 with corresponding $p$-value to be less than 0.05 , indicating that there is a significant impact of perceived usefulness on intention to use. Hence it proved that patients residing in rural areas of Uttarakhand found e-Health useful for them in influencing intention to use such e-health services.

Hypothesis two has been used to analyze the impact of 'perceived ease of use' on 'intention to use'. The analysis result provided a C.R. value of 2.488 and a p-value of 0.013 (less than 0.05) indicating a significant impact of the former on the latter. After having an experience with the e-Health services it became plausible for the rural patients to adopt these facilities with ease. Hence proving perceived use of e-Health services significantly impacts the intention to use e-health services in the state.

Hypotheses three and four (privacy and trust) were additions to the TAM model, which was taken as the base for measuring the impact of various factors on the intention to use and actual use of e-Health. The results obtained showed a C.R of 5.175 and 7.856 respectively, with their corresponding $\mathrm{p}$-values less than 0.05 . Both privacy and trust had a significant impact on the intention to use of eHealth services. The rural patients were established to be reluctant while using e-Health services due to the privacy of their health data. While existing users of e-Health services had no issues with the privacy and trust factors. Hence the combined impact of all the four independent factors shown a variance of $33 \%$ in 'intention to use'

Hypothesis five examined the impact of 'intention to use' on 'actual use'. The final result showed a C.R. value of 10.617 and $p$-value found to be less than 0.05 , indicating a significant impact. The R square value 0.323, depicting that actual use had a variance of $32.3 \%$ due to intention to use. The value of $R$ square has been significant, but the variance brought about was not very high, as the respondents belonged to the rural regions of Uttarakhand, who had little exposure to e-Health facilities.

\section{CONCLUSION \& SUGGESTIONS}

E-health in Uttarakhand during post Covid -19 situation has gained popularity but not impressively impacted the functional areas based on ICT like patient care, laboratory, pharmacy and online registration etc. The patient registration and online appointments have been covered satisfactorily under e-health concept. Improvement in eHealth includes encouraging more online professional fellow system, informed approval process, privacy and empowerment and equity to be encouraged [12][16] for equitable access to health services in rural deprived states of Uttarakhand. [15]

\section{LIMITATIONS \& SCOPE FOR FUTURE RESEARCH:}

The present study is not a comprehensive analysis of the entire health care system in Uttarakhand; it excludes traditional medicine like, AYUSH and Homeopath. But the present empirical study can be further studied by implementing the proposed TAM model to other hilly states of India for effective implementation of e-health services.

\section{References}

1. Aggelidis VP, Chatzoglou PD. (2009). Using a modified technology acceptance model in hospitals. International Journal of Medical Informatics, 78(2), $115-26$.

2. BagozziRP.(2007) The legacy of the technology acceptance model and a proposal for a paradigm shift. Journal of the Association for Information Systems, 8(4), 31-45

3. Byrne, B. M. (2010). Structural Equation Modeling with AMOS: Basic concepts, Applications, and Programming (second ed.). New York: Taylor and Francis Group,LLC.

4. Chellappa, R.K. and Pavlou, P.A. (2002) Perceived Information Security, Financial Liability and Consumer Trust in Electronic Commerce Transactions. Logistics Information Management, 15, 358-368. 
5. Chetley AJ, Davies B, Trude H, Ramirez R. (2006). Improving health connecting people: The role of ICTs in the health sector of developing countries, infoDev ,7(1), 1-65.

6. Chhanabhai P, Holt A.(2007). Consumers are ready to accept the transition to online and electronic records if they can be assured of the security measures. Medscape General Medicine , 9(1), 18-27.

7. Detmer DE.(2003). Building the national health information infrastructure for personal health, health care services, public health, and research. BMC Medical Informatics and Decision Making ,3(1), 21-32

8. Dünnebeil S, Sunyaev A, Blohm I, Leimeister JM, KrcmarH.(2012). Determinants of physicians' technology acceptance for e-health in ambulatory care. International Journal of Medical Informatics, $81(11), 746-60$.

9. Featherman, M.S., \& Pavlou, P.A. (2003). Predicting eServices Adoption: A Perceived Risk Facets Perspective. International Journal of HumanComputer Studies, 59(4), 451-474.

10. Davis F.(1989). Perceived usefulness, perceived ease of use, and user acceptance of information technology, MIS Quarterly, 13, 319-9

11. Giovanis AN, Binioris S, Polychronopoulos G. (2012). An extension of TAM model with IDT and security/privacy risk in the adoption of internet banking services in Greece. EuroMed Journal of Business, April 27

12. Holden RJ, Karsh BT.(2010) The technology acceptance model: Its past and its future in health care. Journal of Biomedical Informatics, 43(1), 159-72.

13. Jaruwachirathanakul B, Fink D.(2005) Internet banking adoption strategies for a developing country: The case of Thailand. Internet Research, 15(3), 295-11.

14. Lee AS.(1991). Integrating positivist and interpretive approaches to organizational research. Organization science, 2(4):342-65.

15. Jung ML, Loria K.(2010). Acceptance of Swedish ehealth services. Journal of Multidisciplinary Healthcare, $3(1), 55-67$.

16. Khan SZ, Shahid Z, Hedstrom K, Andersson A.(2012). Hopes and fears in implementation of electronic health records in Bangladesh. The Electronic Journal of Information Systems in Developing Countries, 54(8), $1-18$.
17. Kim NE, Han SS, Yoo KH, Yun EK.(2012). The impact of user's perceived ability on online health information acceptance. Telemedicine and e-Health, 18(9), 70308.

18. King WR, He J.(2006). A meta-analysis of the technology acceptance model. Information \& Management,43(6), 740-55.

19. Korgaonkar, P. and Wolin, L.D. (2002), "Web usage, advertising, and shopping: relationship patterns", Internet Research, Vol. 12 No. 2, pp. 191-204.

20. Mair FS, Carl M, Catherine O, Tracy F, Frank S, Elizabeth M.(2012). Factors that promote or inhibit the implementation of e-health systems: An explanatory systematic review. Bulletin of the World Health Organization, 90(5), 357-64.

21. Sheraz U, Inayatullah S, Shah A.(2013) E-health futures in Bangladesh. Foresight, 15(3), 177-89.

22. Taylor, S., \& Todd, P. A. (1995a). Assessing IT usage: The role of prior experience. MIS Quarterly, 19, 561-570.

23. [25] Tierney, WM, Kanter, AS, Fraser, HS, Bailey, C.(2010) A toolkit for e-health partnerships in lowincome nations. Health Affairs, 29(2), 268-73.

24. Tung FC, Chang SC, Chou CM.(2008). An extension of trust and TAM model with IDT in the adoption of the electronic logistics information system in HIS in the medical industry. International Journal of Medical Informatics, 77 (5), 324-35.

25. Venkatesh, V., Davis, F. D., \& Morris, M. G. (2007). Dead or Alive? The development, trajectory and future of technology adoption research. Journal of the Association for Information Systems, 8(4), 267-286.

26. Wickramasinghe NS, Fadlalla AM, Geisler E, Schaffer JL.(2005). A framework for assessing e-health preparedness. International Journal of Electronic Healthcare, $1(3), 316-34$

27. Wilkowska W, Martina Z.(2012). Privacy and data security in E-health: Requirements from the user's perspective. Health Informatics Journal, 18(3), 191201.

28. Wu JH, Wang SC, Lin LM.(2007). Mobile computing acceptance factors in the healthcare industry: A structural equation model. International Journal of Medical Informatics ,76(1), 66-77. 


\section{APPENDIX}

\begin{tabular}{|c|c|}
\hline CONSTRUCT & MEASUREMENT ITEMS \\
\hline $\begin{array}{l}\text { Perceived } \\
\text { Usefulness(PU) }\end{array}$ & $\begin{array}{l}\text { PU1: Using the e-Health services will improve my life quality } \\
\text { PU2: Using the e-Health services will make my life more convenient } \\
\text { PU3: Using the e-Health services will make me more effective in my life } \\
\text { PU4: Overall, I find the e-Health services to be useful in my life }\end{array}$ \\
\hline $\begin{array}{l}\text { Perceived Ease of Use } \\
\text { (PEU) }\end{array}$ & $\begin{array}{l}\text { PEU1: Learning to operate the e-Health services will be easy for me } \\
\text { PEU2: I can easily become skillful at using the e-Health services } \\
\text { PEU3: I can get the e-Health services to do what I want it to do } \\
\text { PEU4: Overall, the e-Health services are easy to use }\end{array}$ \\
\hline Privacy (PRI) & $\begin{array}{l}\text { PRI1: I believe that privacy of e-Health participants is protected } \\
\text { PRI2: I believe personal information stored in e-Health system is safe } \\
\text { PRI3: I believe e-Health systems to keep participants' information secure }\end{array}$ \\
\hline Trust (TRU) & $\begin{array}{l}\text { TRU1: Based on my experience with the e-Health in the past, I know it is trustworthy } \\
\text { TRU2: Based on my experience with the e-Health in the past, I know it is not opportunistic } \\
\text { TRU3: Based on my experience with the e-Health in the past, I know that it keeps its } \\
\text { promises to its patient }\end{array}$ \\
\hline Intention to Use (INT) & $\begin{array}{l}\text { INT1: I have high intention to use the e-Health service } \\
\text { INT2: I intend to learn about using e-Health services } \\
\text { INT3: I plan to use e-Health services to manage my health }\end{array}$ \\
\hline Actual Use (ACT) & $\begin{array}{l}\text { ACT1: e-Health service is a pleasant experience } \\
\text { ACT2: I use e-Health service currently } \\
\text { ACT3: I spend a lot of time on e-Health service }\end{array}$ \\
\hline
\end{tabular}

